\title{
Effects of Topography and Modified Layer by Plasma-Shot Treatment on High-Speed Steel
}

\author{
Yorihito Shibata $^{1} \cdot$ Yusuke Sakairi $^{1} \cdot$ Keita Shimada $^{1} \cdot$ Masayoshi Mizutani $^{1} \cdot$ Tsunemoto Kuriyagawa $^{2}$
}

Received: 13 February 2020 / Revised: 19 March 2020 / Accepted: 2 May 2020 / Published online: 24 May 2020

(c) The Author(s) 2020

\begin{abstract}
In this study, plasma shot (PS) treatment was applied to high-speed steel (HSS) surfaces using a titanium carbide electrode to confirm the effect of discharge current $\left(I_{\mathrm{p}}\right)$ on the formation of a single dimple and analyze a modified layer. The roughness of modified surfaces increased when $I_{\mathrm{p}}$ increased, and energy-dispersive X-ray spectrometry showed an increase in titanium atom density when $I_{\mathrm{p}}$ and electrode consumption volume $\left(V_{\mathrm{e}}\right)$ increased. A friction test confirmed that the modified surface's friction was reduced by discharge dimples under low-load conditions. Vickers hardness test confirmed that the hardness of the modified surface was 300-600 HV higher than that of an untreated HSS surface. Moreover, it increased with an increase in $I_{\mathrm{p}}$. However, application of PS treatment to the edge of surfaces on the workpiece caused shape deterioration. The deterioration size of the edge of the modified layer increased when $I_{\mathrm{p}}$ increased. To solve this issue, we propose a novel method named position-adjusted PS (PA-PS) treatment. PA-PS treatment is used to adjust the end of the electrode in the order of tens of micrometers from the edge of the workpiece to avoid the deterioration of the edge form. Under $I_{\mathrm{p}}=21 \mathrm{~A}$, PA-PS formed a modified layer without deteriorating the edge shape of the workpiece, thus confirming the PS characteristics applied to HSS surfaces. Moreover, PA-PS treatment solved the shape deterioration of the edge on modified surfaces via PS treatment.
\end{abstract}

Keywords Plasma-shot treatment $\cdot$ Electric discharge machining $\cdot$ Surface modification $\cdot$ High-speed steel $\cdot$ Tool wear . Friction

\section{Introduction}

At present, products that have considerably improved our standard of living are produced by various manufacturing methods. In machine processing, machine parts are accurately produced using machine tools such as lathes, milling machines, drilling machines, and machining centers. The industry depends on the machining process to machine the various shapes of products using cutting tools. High-efficiency cutting has been increasingly demanded for high-mix, low-volume production; however, tool life is a major bottleneck for realizing more efficient manufacturing because cutting tools are exposed to severe environments of high

Masayoshi Mizutani

masayoshi.mizutani.b6@tohoku.ac.jp

1 Graduate School of Engineering, Tohoku University, 6-6-01, Aoba, Aramakiaza, Aobaku, Sendaishi, Miyagi, Japan

2 Graduate School of Biomedical Engineering, Tohoku University, 6-6-01, Aoba, Aramakiaza, Aobaku, Sendaishi, Miyagi, Japan temperatures and pressures at high cutting speeds, which considerably increases the wear rate. To protect such tools from wear, surfaces are treated using conventional surface treatment technology, such as chemical vapor deposition (CVD) and physical vapor deposition (PVD), to form wearproof layers [1]. These surface treatment technologies are important for increasing the machining performance of cutting tools [2]. The disadvantages of these surface treatment technologies include low adhesion of coating and thickness nonuniformity when applied to complex surfaces. However, plasma-shot (PS) treatment can overcome certain disadvantages of the conventional technologies [3].

PS treatment was developed by applying electric discharge machining (EDM). EDM is a manufacturing method that can be used to machine hard materials into complex shapes with high precision [4]. PS treatment is completely the opposite of EDM and transfers electrode materials to the workpiece surface to form modified surfaces. Figure 1 shows the mechanism of PS treatment [5]. In this process, arc discharges occur between the workpiece and the electrode, which partially melts and transfers to the workpiece 


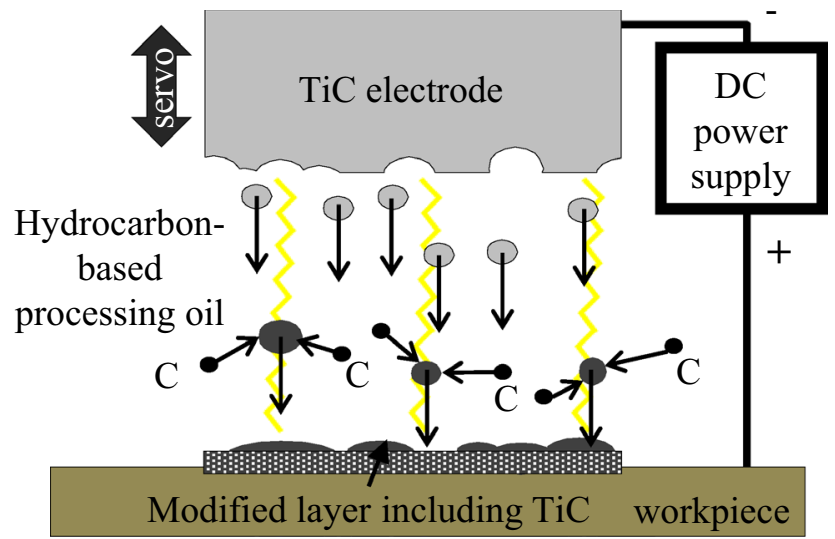

Fig. 1 Mechanism of PS treatment [5]

surface during the discharge. In fact, 10,000 arc discharges occur every second, and the gap between the electrode and workpiece during processing is controlled in the order of tens of micrometers using servo motors [6]. Spectroscopic analysis has confirmed that the temperature of the arc discharge reaches $\sim 6000-7000 \mathrm{~K}$ [7]. Moreover, the heat flux at $>109 \mathrm{~W} / \mathrm{m}^{2}$ from the arc discharge instantaneously melts and evaporates the electrode. The molten electrode material is laminated in the molten pool on the surface of the workpiece. Usually, the green compact electrode, which is easily consumed, is used to transfer the electrode material to the workpiece surface during processing [8]. The advantages of PS treatment are as follows [5]:

1. The deformation on workpiece surfaces is considerably less because the shrinkage of the workpiece is limited to a shallow range via local pulse discharge during PS treatment.

2. Local treatment is possible by controlling the shape of the electrode material and vibration pattern during processing.

3. The modified layer is highly adhesive because the electrode material is melted by the heat of the arc discharge and mixes with the workpiece material.

4. PS treatment uses appropriate electrode materials to yield various surface characteristics [9]. Previously, a modified layer with high hardness was successfully formed on Fe-based materials using a titanium carbide (TiC) electrode [10].

In conventional research, the detailed characteristics of high-speed steel (HSS) after PS treatment have not been studied [3, 11]. Therefore, to clarify HSS characteristics after PS treatment, we observed and analyzed the shape of a single dimple sample and the modified surface, the amount of transferred titanium (Ti) atoms, and the parameters (e.g.,
Sa, Sku, and Ssk). Then, we evaluated the mechanical characteristics of modified surfaces by the Vickers hardness (HV) and friction tests. Finally, a new PS treatment was developed that addressed shape deterioration in the cutting edge by adjusting the electrode's position, which is known as position-adjusted PS (PA-PS) treatment. This treatment solves the disadvantage of shape deterioration known as "sagging" on application of PS treatment to the edge of cutting tools.

\section{Plasma-Shot Characteristics of HSS Workpiece}

\subsection{Methodology}

The electrode material used in the experiment was TiC, which improved surface wear resistance. The workpiece material was HSS (C: $2.0 \%$, Si: $0.5 \%$, Mn: $0.3 \%$, Cr: $3.8 \%$, Mo: $2.5 \%$, V: $5.1 \%$, W: $14.3 \%$, Co: $11.0 \%$ ). In this experiment, an electric discharge machine (Mitsubishi Electric Corporation, ES041-A) was used. Moreover, for this process, the workpiece and TiC electrode had positive polarity. Figure 2 and Table 1 show the setup and PS treatment conditions, respectively.

\subsection{Observation of a Single Dimple}

In this study, scanning electron microscopy (SEM), white light interferometry (WLI), and energy-dispersive X-ray

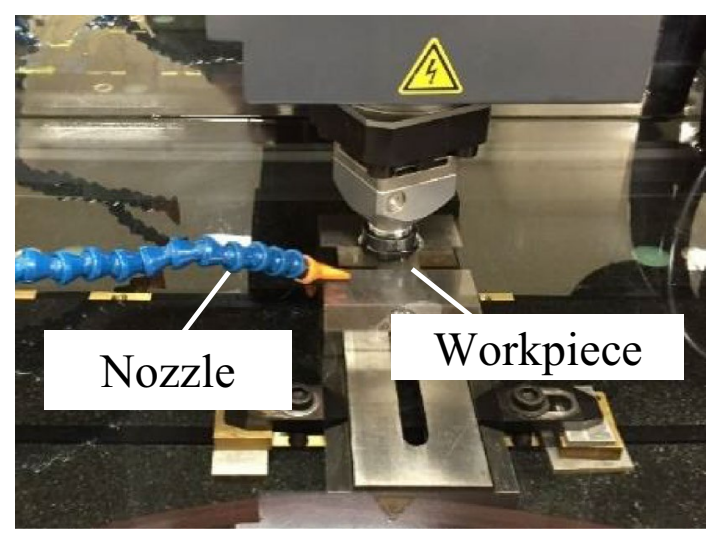

Fig. 2 Setup of PS treatment

Table 1 PS treatment conditions

\begin{tabular}{ll}
\hline Voltage & $320 \mathrm{~V}$ \\
Pulse duration & $8 \mu \mathrm{s}$ \\
Pause time & $256 \mu \mathrm{s}$ \\
Electrode materials & $\mathrm{TiC}$ \\
\hline
\end{tabular}


diffraction (EDX) were used to evaluate the surfaces of the modified layers. A TiC electrode was used to apply PS treatment to HSS surfaces to confirm the effect of discharge current $\left(I_{\mathrm{p}}\right)$ on the formation of a single dimple, which was observed using SEM and WLI. Table 1 lists the experimental conditions in which $I_{\mathrm{p}}$ was $1,3,10$, and 21 A. A single dimple was observed because the modified surface was the outcome of a series of single dimples [12]. Figure 3 shows the SEM images of the single dimple at each $I_{\mathrm{p}}$. Figure 4 shows the diameter of the single dimple in each $I_{\mathrm{p}}$ measured from Fig. 3 . We used the WLI to measure the 3D topography of a single discharge and calculated the average value of the three points where the height of peaks and depth of craters were large for the measurement area of each $I_{\mathrm{p}}$. Figure 5 shows the roughness of the single dimple of each $I_{\mathrm{p}}$. The round shape of the single dimple formed in each $I_{\mathrm{p}}$ was confirmed in Fig. 3; the black part in the image was the crater. The shapes of the single dimples were complicated by the effect of the surrounding conditions and the flow of the machining fluid when they were once melted and resolidified. The diameters of the individual dimples increased along with an increase in $I_{\mathrm{p}}$; however, their growth became saturated after $I_{\mathrm{p}}=10 \mathrm{~A}$ in Fig. 4. A previous study reported that the capacity of workpiece melting was increased by an increase in discharge current energy [13]. Thus, the diameter of a single dimple increased along with an increase in $I_{\mathrm{p}}$. On the other hand, dimples with the same diameters were formed under $I_{\mathrm{p}}=10$ and $21 \mathrm{~A}$. Thus, we confirmed that the height of the peak and the depth of the crater in the discharge dimple increased along with an increase in $I_{\mathrm{p}}$; however, the height of the peak saturated after $I_{\mathrm{p}}=10 \mathrm{~A}$ (Fig. 5). This tendency was similar to that of cast iron [11].

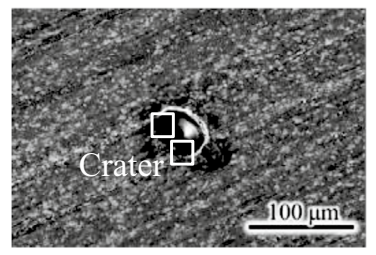

(a) $I_{\mathrm{p}}=1 \mathrm{~A}$.

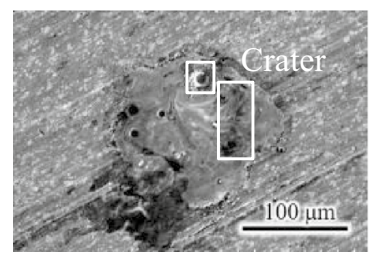

(c) $I_{\mathrm{p}}=10 \mathrm{~A}$

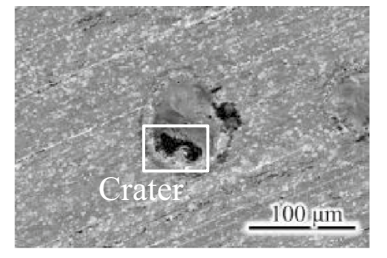

(b) $I_{\mathrm{p}}=3 \mathrm{~A}$

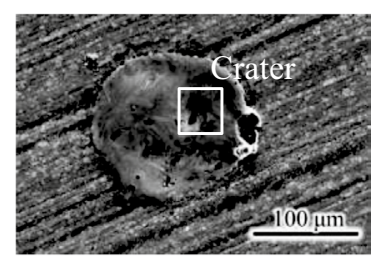

(d) $I_{\mathrm{p}}=21 \mathrm{~A}$
Fig. 3 SEM images of the single dimple on each $I_{\mathrm{p}}$

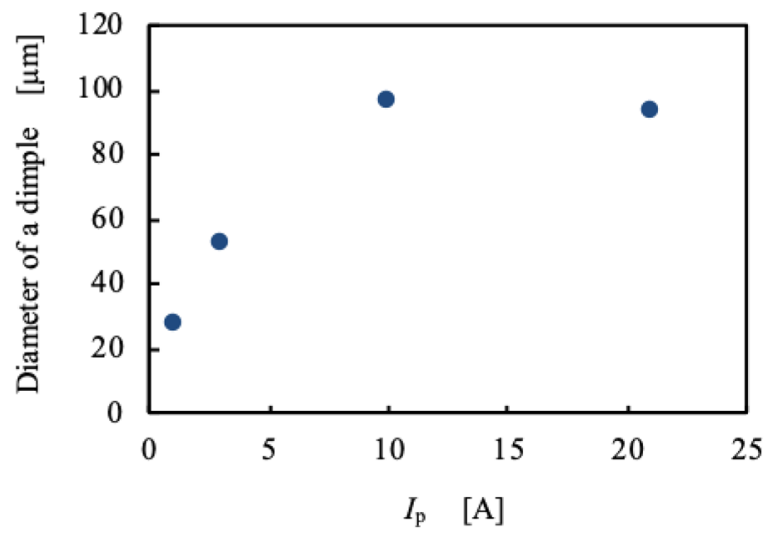

Fig. 4 Relationship between the diameter of a single dimple and $I_{\mathrm{p}}$ when $I_{\mathrm{p}}$ increases

\subsection{Observation and Analysis of the Modified Layer}

We used SEM to observe the surfaces of modified layers when $I_{\mathrm{p}}$ and the electrode consumption volume $\left(V_{\mathrm{e}}\right)$ were varied. The experimental conditions were the same as the ones given in Table 1. The HSS surface was subjected to PS treatment under $I_{\mathrm{p}}=3,10$, and $21 \mathrm{~A}$ and $V_{\mathrm{e}}=0.025,0.05$, and $0.1 \mathrm{~mm}$. The PS treatment time was increased along with an increase in $V_{\mathrm{e}}$. Figure 6 shows the SEM image of the modified layer when $I_{\mathrm{p}}$ and $V_{\mathrm{e}}$ changed. The modified layer had rough surfaces under each condition, and the size and number of dimples increased when $I_{\mathrm{p}}$ increased under each $V_{\mathrm{e}}$.

In addition, we used EDX to evaluate the amount of transferred titanium (Ti) atoms from the $\mathrm{TiC}$ electrode to the surface on the modified layer when $I_{\mathrm{p}}$ and $V_{\mathrm{e}}$ were varied. Figure 7 shows the change in the Ti atomic number concentration when $I_{\mathrm{p}}$ and $V_{\mathrm{e}}$ changed. An increase in the Ti atomic

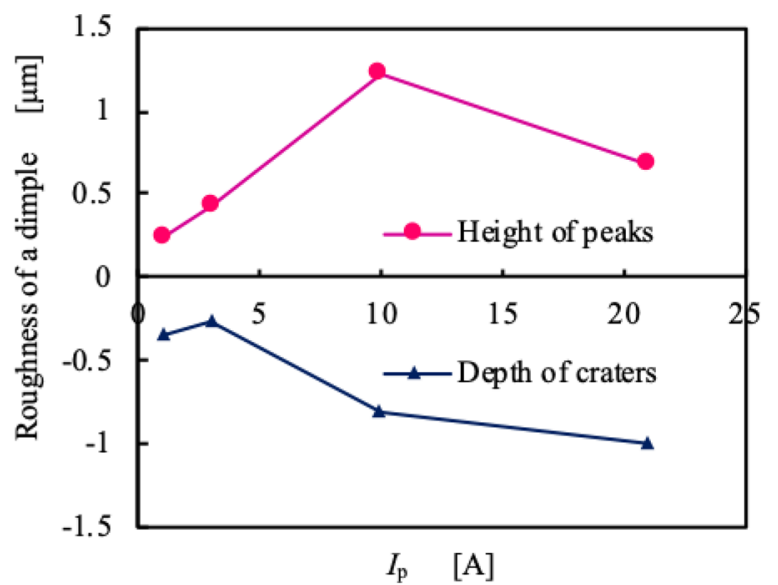

Fig. 5 Relationship between the roughness of a single dimple and $I_{\mathrm{p}}$ when $I_{\mathrm{p}}$ increases 

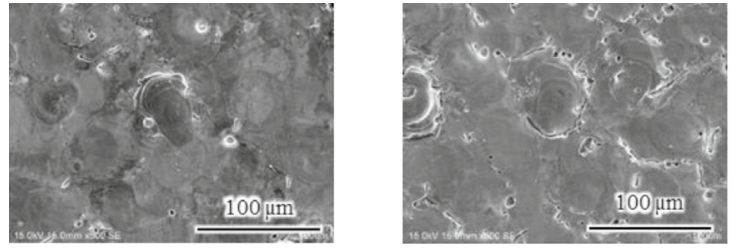

(a) $I_{\mathrm{p}}=3 \mathrm{~A}, V_{\mathrm{e}}=0.025 \mathrm{~mm}$

(b) $I_{\mathrm{p}}=3 \mathrm{~A}, V_{\mathrm{e}}=0.05 \mathrm{~mm}$
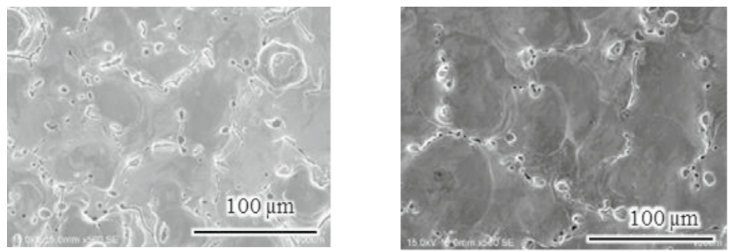

(c) $I_{\mathrm{p}}=3 \mathrm{~A}, V_{\mathrm{e}}=0.1 \mathrm{~mm}$

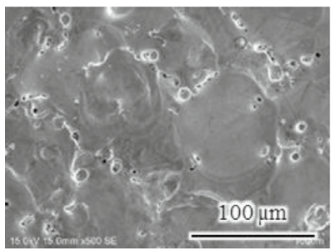

(d) $I_{\mathrm{p}}=10 \mathrm{~A}, V_{\mathrm{e}}=0.025 \mathrm{~mm}$

(e) $I_{\mathrm{p}}=10 \mathrm{~A}, V_{\mathrm{e}}=0.05 \mathrm{~mm}$

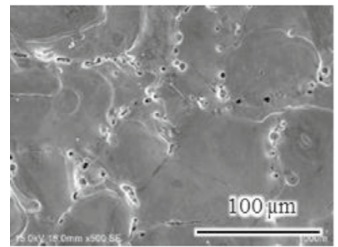

(g) $I_{\mathrm{p}}=21 \mathrm{~A}, V_{\mathrm{e}}=0.025 \mathrm{~mm}$

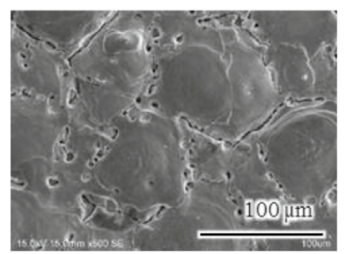

(f) $I_{\mathrm{p}}=10 \mathrm{~A}, V_{\mathrm{e}}=0.1 \mathrm{~mm}$

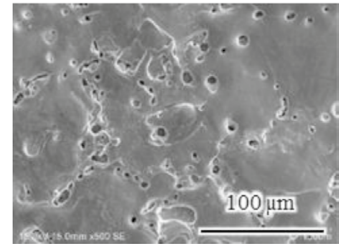

(h) $I_{\mathrm{p}}=21 \mathrm{~A} V_{\mathrm{e}}=0.05 \mathrm{~mm}$

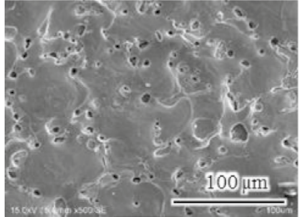

(i) $I_{\mathrm{p}}=21 \mathrm{~A}, V_{\mathrm{e}}=0.1 \mathrm{~mm}$

Fig. 6 SEM images of the modified layer when $I_{\mathrm{p}}$ and $V_{\mathrm{e}}$ are varied

number concentration along with an increase in $V_{\mathrm{e}}$ for each $I_{\mathrm{p}}$ was confirmed. The thickness of the TiC-modified layer increased along with an increase in $V_{\mathrm{e}}$. Moreover, a considerable increase was observed in the $\mathrm{Ti}$ atomic number concentration under $I_{\mathrm{p}}=3 \mathrm{~A}$ and $V_{\mathrm{e}}=0.1 \mathrm{~mm}$. This increase was due to the increase in transferred TiC from the electrodes to workpiece surfaces owing to longer treatment time and a decrease in $I_{\mathrm{p}}$.

\subsection{Evaluation of the Modified Surface Topography}

The roughness of the modified layer is closely related to the friction of the surface. Therefore, we analyzed the surface

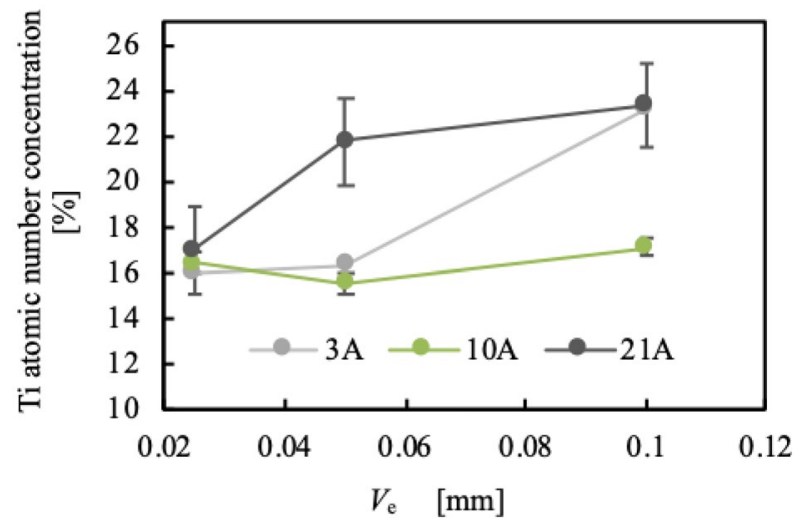

Fig. 7 Change in Ti atomic number concentration when $I_{\mathrm{p}}$ and $V_{\mathrm{e}}$ changed

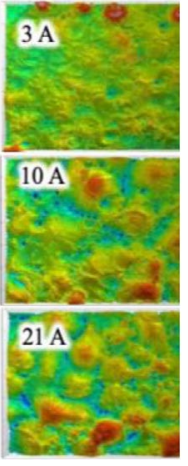

(a) $V_{\mathrm{e}}=0.025 \mathrm{~mm}$
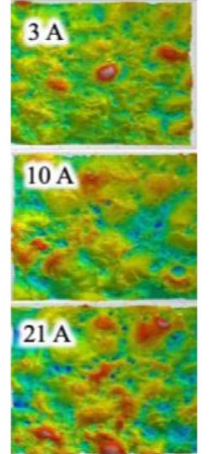

(b) $V_{\mathrm{e}}=0.05 \mathrm{~mm}$

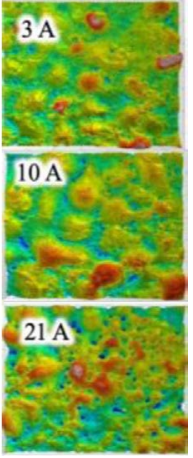

(c) $V_{\mathrm{e}}=0.1 \mathrm{~mm}$
Fig. 8 Topography of modified surfaces when $I_{\mathrm{p}}$ and $V_{\mathrm{e}}$ are varied

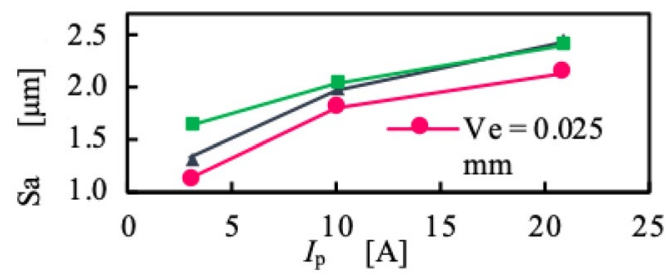

Fig. 9 Relationship between Sa of modified surfaces and $I_{\mathrm{p}}$ when $I_{\mathrm{p}}$ increases on each $V_{\mathrm{e}}$

and evaluated its parameters (e.g., Sa, Sku, and Ssk) when $V_{\mathrm{e}}$ and $I_{\mathrm{p}}$ were varied. Figure 8 shows the topography of the modified surface evaluated by WLI. The height difference between the top and bottom and roughness of the modified layer increased. The increase in roughness in the single dimple along with an increase in $I_{\mathrm{p}}$ affected this result. The roughness of the modified layer did not change when $V_{\mathrm{e}}$ increased. Figure 9 shows the quantitative evaluation of the $\mathrm{Sa}$ increase when $I_{\mathrm{p}}$ increased. The increase in Sa was due 
Table 2 Relationship between Sku and the roughness of surfaces

\begin{tabular}{ll}
\hline $\mathrm{Sku}>3$ & Surfaces have a sharp roughness \\
$\mathrm{Sku}=3$ & Height distribution is normal \\
$\mathrm{Sku}<3$ & Surfaces have a dull roughness \\
\hline
\end{tabular}

Table 3 Relationship between Ssk and the symmetry of surfaces

\begin{tabular}{ll}
\hline Ssk $>0$ & Surfaces have many mounds \\
Ssk $=0$ & Height distribution is symmetrical \\
Ssk $<0$ & Surfaces have many craters \\
\hline
\end{tabular}

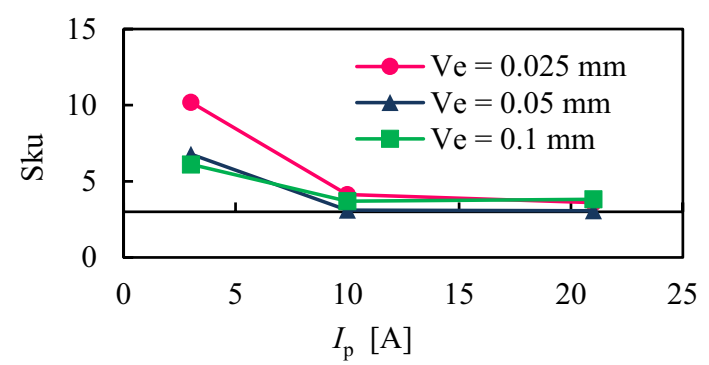

Fig. 10 Relationship between Sku of modified surfaces and $I_{\mathrm{p}}$ when $I_{\mathrm{p}}$ increases on each $V_{\mathrm{e}}$

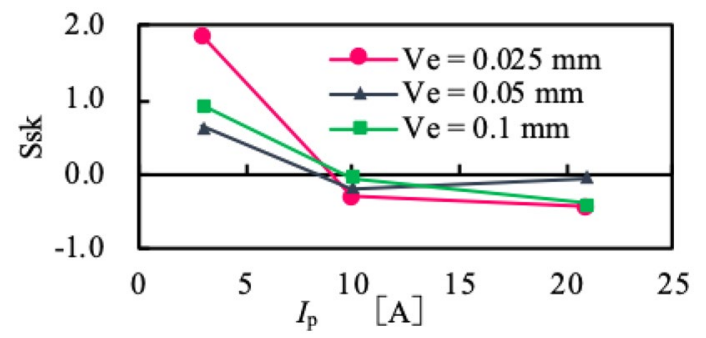

Fig. 11 Relationship between Ssk of modified surfaces and $I_{\mathrm{p}}$ when $I_{\mathrm{p}}$ increases on each $V_{\mathrm{e}}$

to the high treatment temperature. The change in Sa because of the increase in $V_{\mathrm{e}}$ was not confirmed. Sku is the sharpness of the surface, while Ssk is the symmetry of the surface and characterizes height distribution [14]. Tables 2 and 3 show the relationship between Sku and the sharpness of the surfaces and the relationship between Ssk and the symmetry of the surfaces, respectively. Figures 10 and 11 show Sku and Ssk of the modified layer. Figure 10 shows that the surface treated under $I_{\mathrm{p}}=3 \mathrm{~A}$ has $\mathrm{Sku}>3$, which suggests a sharp roughness of shape. The surface treated under $I_{\mathrm{p}}=10 \mathrm{~A}$ and $21 \mathrm{~A}$ has $\mathrm{Sku}<3$, which indicates a dull roughness of shape. Figure 11 shows that the surface treated under $I_{\mathrm{p}}=3 \mathrm{~A}$ has Ssk $>0$, which shows that the surface has many peaks. The surface treated under $I_{\mathrm{p}}=10$ and $21 \mathrm{~A}$ has Ssk $<0$, which

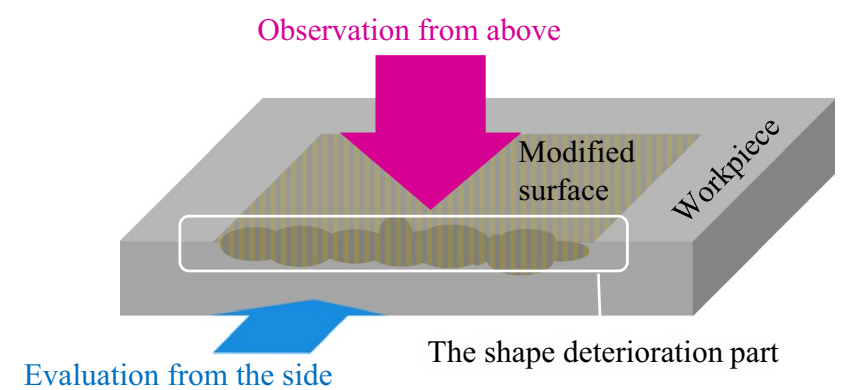

Evaluation from the side

Fig. 12 Schematic of observation and evaluation

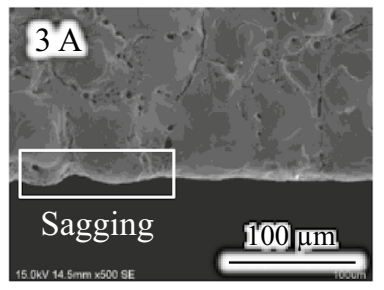

(a) $I_{\mathrm{p}}=3 \mathrm{~A}$

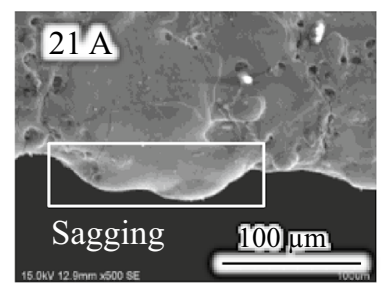

(b) $I_{\mathrm{p}}=21 \mathrm{~A}$
Fig. 13 SEM images of the shape deterioration (sagging) on the edge of the workpiece on each $I_{\mathrm{p}}$

indicates that the surface has multiple craters. The surface treated under $I_{\mathrm{p}}=10$ and $21 \mathrm{~A}$ has low friction because the dimples supply oil to the surfaces because of hydrodynamic lubrication.

\subsection{Evaluation of the Edge Shape of Modified Surfaces}

We applied PS treatment to the edge of cutting tools to treat the edge of the HSS workpiece. We used SEM and WLI to observe and evaluate the edges of the treated surfaces from above and the side, respectively, to confirm the relationship between the change in $I_{\mathrm{p}}$ and the generation of "sagging." The experimental conditions were the same as those given in Table 1 , and $V_{\mathrm{e}}=0.05 \mathrm{~mm}$. Figure 12 shows the observation and evaluation methods. Figure 13 shows that the shape deterioration called "sagging" on the edge of the workpiece was generated in each $I_{\mathrm{p}}$. The size of sagging increased when $I_{\mathrm{p}}$ increased. This result can be attributed to the tendency of the diameter of the dimple and Sa on the surfaces to increase when $I_{\mathrm{p}}$ increases. Figure 14 shows the topography of the edge of workpieces from the side of each $I_{\mathrm{p}}$. The topography under $I_{\mathrm{p}}=21$ A shows the partial error of high roughness to the side. The heights of sagging to the side are $\sim 8 \mu \mathrm{m}$ under $I_{\mathrm{p}}=3$ and $\sim 18 \mu \mathrm{m}$ under $I_{\mathrm{p}}=21 \mathrm{~A}$. The tendency of the increase in shape deterioration was the same as that of 


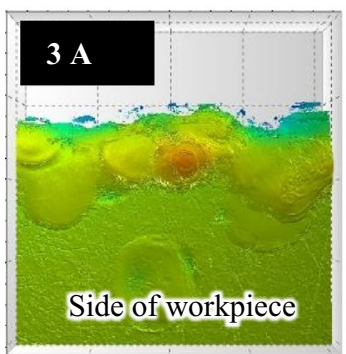

(a) $I_{\mathrm{p}}=3 \mathrm{~A}$

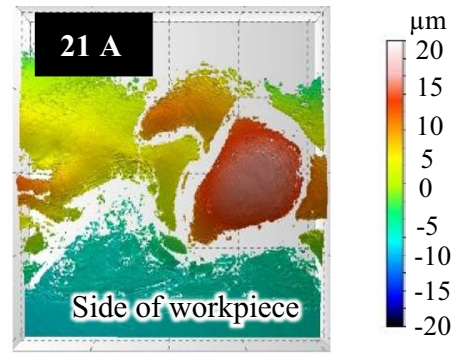

(b) $I_{\mathrm{p}}=21 \mathrm{~A}$
Fig. 14 Topography of the edge of workpieces from the side for each $I_{\mathrm{p}}$

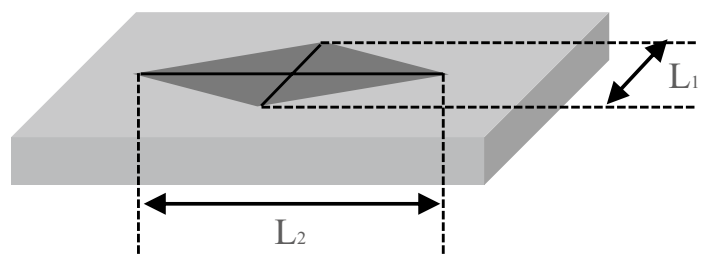

Fig. 15 Image of the generated indentations

the diameter of dimples in Fig. 4. The heights of sagging to the side are smaller than the diameters of dimples at each $I_{\mathrm{p}}$.

\section{Mechanical Characteristics of the Treated Surfaces}

We conducted HV and friction tests to evaluate the mechanical characteristics of the treated surfaces by PS treatment. We used the HV test to measure the hardness of the treated surface and investigate the change in HV when $I_{\mathrm{p}}$ was increased. In this test, a microscope was used to determine the analysis area, and an indent was generated by a Vickers indenter. Hardness was measured by dividing the applied load $\mathrm{P}$ by the surface area of the generated indentation. Figure 15 shows the generated indentations. The surface area was calculated using $L_{1}$ and $L_{2}$. The following equation was used for HV:

$\mathrm{HV}=189.1 \times 2 P /\left(L_{1}+L_{2}\right)^{2}$

where $L_{1}$ and $L_{2}$ are the diagonal lengths of the diamondshaped indentations and $\mathrm{P}$ is the load. Table 2 shows the test conditions. We evaluated the HSS workpiece and treated the surfaces in Table 1 for each $V_{\mathrm{e}}=0.05 \mathrm{~mm}$ when $I_{\mathrm{p}}$ increased. Figure 16 shows HV when $I_{\mathrm{p}}$ increased. The HV test confirmed that the hardness of the modified surface was 300-600 HV larger than that of an untreated HSS surface. Moreover, the hardness increased along with an

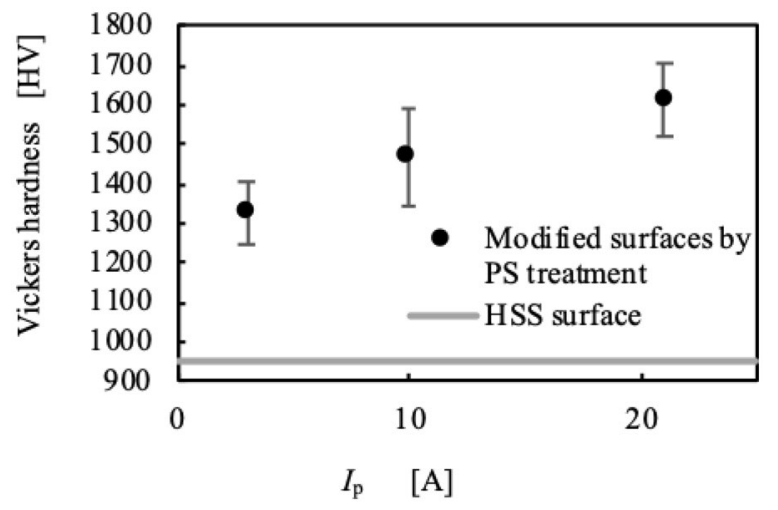

Fig. 16 Relationship between $\mathrm{HV}$ and $I_{\mathrm{p}}$ when $I_{\mathrm{p}}$ increases

Table 4 HV test conditions

\begin{tabular}{ll}
\hline Indenter type & Vickers \\
Test load (mN) & 1000 \\
Retention time (s) & 5 \\
Lens magnification & 100 times \\
Load speed (mN/s) & 70.6 \\
Number of indentations & 10 \\
\hline
\end{tabular}

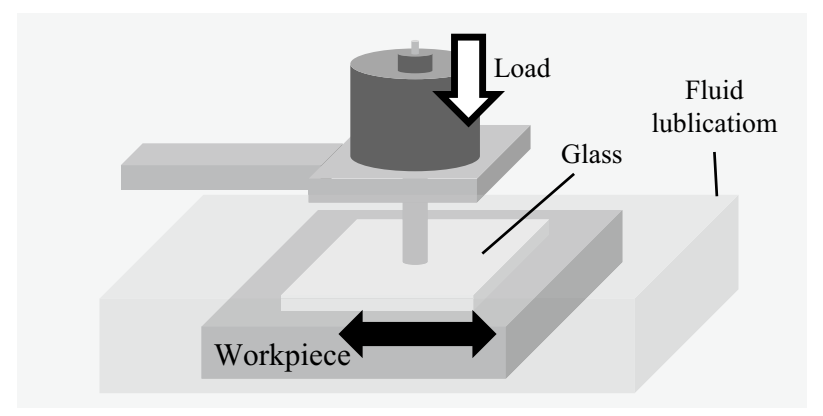

Fig. 17 Schematic of reciprocating friction test with a glass surface under fluid lubrication

increase in $I_{\mathrm{p}}$, primarily because the thickness of the TiCmodified layer increased along with an increase in the depth of the treated area when $I_{\mathrm{p}}$ increased in the PS treatment process.

We conducted a reciprocating friction test under fluid lubrication to evaluate the friction characteristics of the modified surfaces. Table 3 gives the test conditions, whereas Table 4 gives the lubricating oil specifications. Figure 17 shows the reciprocating friction test with a glass surface under fluid lubrication. The kinematic viscosity of fluid was $8.108 \mathrm{~s} / \mathrm{mm}^{2}$, and the friction test was used to evaluate four types of workpieces: HSS workpieces and modified workpieces by PS treatment under the conditions 


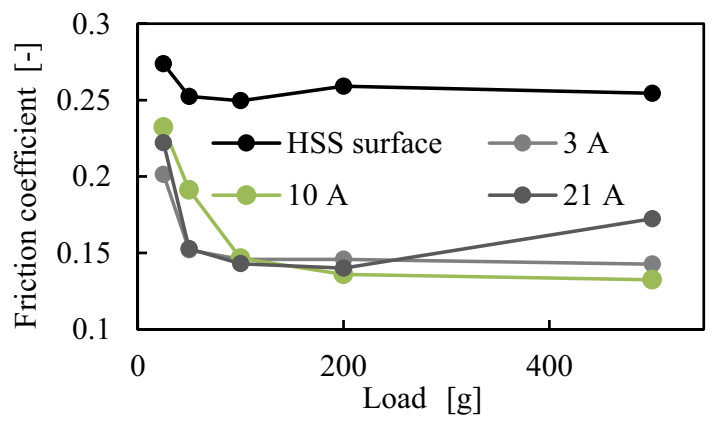

Fig. 18 Relationship between friction coefficient and load at any surface

Table 5 Reciprocating friction test conditions

\begin{tabular}{ll}
\hline Load $(\mathrm{g})$ & 25,50, \\
& 100, \\
& 200,500 \\
Reciprocating speed (cpm) & 180 \\
Linear velocity (mm/s) & 30 \\
Reciprocating width (mm) & 5 \\
Test time (s) & 600 \\
\hline
\end{tabular}

Table 6 Lubrication oil specifications

\begin{tabular}{ll}
\hline Kinematic viscosity $\left(\mathrm{s} / \mathrm{mm}^{2}\right)$ & 8.108 \\
Density $\left(\mathrm{g} / \mathrm{cm}^{3}\right)$ & 0.869 \\
\hline
\end{tabular}

of $I_{\mathrm{p}}=3,10$, and $21 \mathrm{~A}$ and $V_{\mathrm{e}}=0.1 \mathrm{~mm}$. The load was increased from 25 to $500 \mathrm{~g}$ in the friction test. Figure 18 shows the friction test results. The friction coefficient of the modified surfaces was $\sim 0.05-0.10$ less than that of the HSS surface in any load. We speculate that dimples on the modified surfaces remained and transferred fluid between the modified surfaces and the glass during the reciprocating movement. Friction reduction by discharge dimples was confirmed, especially under low-load conditions from 25 to $100 \mathrm{~g}$. This reduction was attributed to the wedge effect, generating hydrodynamic pressure in the narrow gaps [15]. However, the friction coefficient at $I_{\mathrm{p}}=21 \mathrm{~A}$ increased under high-load condition from $200 \mathrm{~g}$, which was attributed to contact between peaks on the modified surfaces and the glass because gaps decreased as the load increased. Therefore, the friction reduction effect owing to hydrodynamic pressure was significant under low load, but the friction increase was generated by the contact between peaks on the modified surfaces and the glass under large load. We concluded that PS treatment improved the friction characteristics of the surface materials arising from a decrease in the friction coefficient under fluid lubrication (Tables 5, 6).

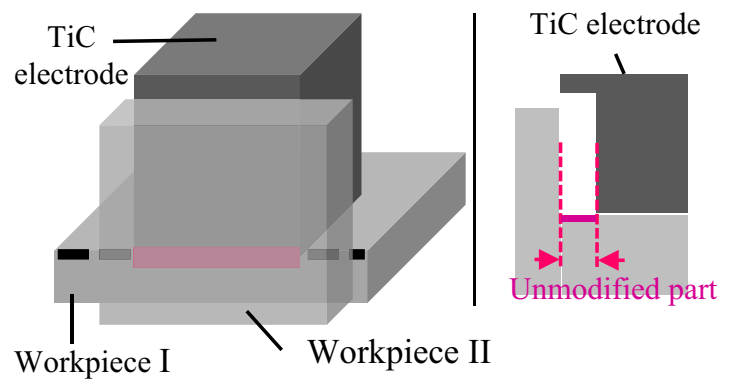

Fig. 19 Position-adjusted PS (PA-PS) treatment

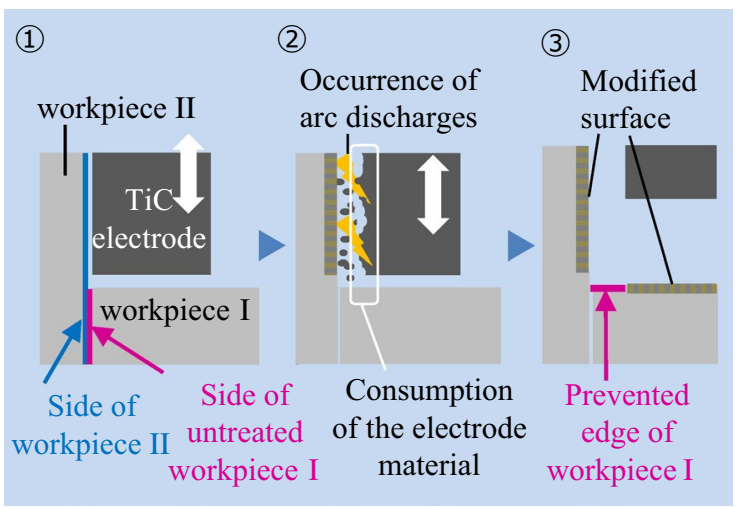

Fig. 20 Process and mechanism of PA-PS treatment

\section{Position-Adjusted PS Treatment}

We discovered that PS treatment had the disadvantage of causing shape deterioration known as "sagging" when it was applied to the edge of the cutting tools in Sect. 2.5. The size of sagging increased as $I_{\mathrm{p}}$ increased; thus, this study introduces a new PS treatment that addresses shape deterioration in the cutting edge by adjusting the electrode's position, which is known as position-adjusted PS (PA-PS) treatment.

PS treatment was applied to the edge of the HSS workpiece at $I_{\mathrm{p}}=3$ and $21 \mathrm{~A}$. The experimental conditions were the same as those given in Table 1 , and $V_{\mathrm{e}}=0.05 \mathrm{~mm}$. Figures 19 and 20 show the appearance and process of PA-PS treatment, respectively. First, this treatment adjusted the side of untreated workpiece I to the side of workpiece II (Fig. 20). Second, the position of the end of the electrode material was adjusted to the edge of workpiece I because of the consumption of the side surface of the electrode material by arc discharges between the side of the electrode material and that of workpiece II during the treatment process. Finally, this treatment prevented the edge of workpiece I from causing shape deterioration because of the adjusted electrode material in the PS process. After the 

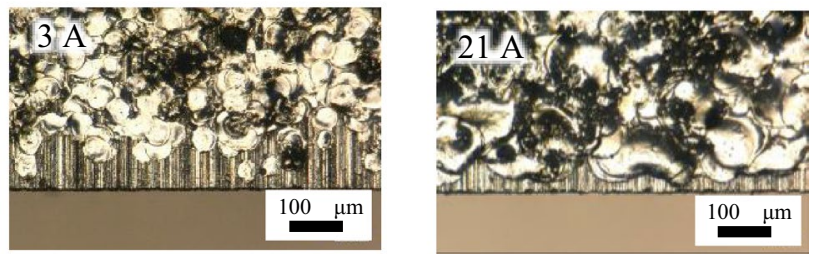

Fig. 21 DM images of the edge of the modified surfaces by PA-PS treatment for each $I_{\mathrm{p}}$

above process, we used PA-PS treatment to observe and evaluate the edge of the modified surface.

Figure 21 shows the digital microscopy (DM) images of the edge of the modified surfaces using PA-PS treatment. The black and silver parts represent craters and peaks on the modified surfaces in Fig. 21, respectively. The edges of the modified surfaces under $I_{\mathrm{p}}=3$ and 21 A were successfully prevented from causing shape deterioration (Fig. 21). We used a DM to measure the maximum distance from the edge of the workpiece to the modified surface under $I_{\mathrm{p}}$ to evaluate the appropriate $I_{\mathrm{p}}$. The measurement results show that the maximum distance from the edge of the workpiece to the modified surface is $\sim 150 \mu \mathrm{m}$ when $I_{\mathrm{p}}=3 \mathrm{~A}$ and $\sim 80 \mu \mathrm{m}$ when $I_{\mathrm{p}}=21 \mathrm{~A}$. This indicates that PA-PS treatment under $I_{\mathrm{p}}=21$ A can successfully treat the edge of the modified surface. We argue that the distance from the edge of the workpiece to the modified surface was reduced because of an increase in the diameter of a single dimple when $I_{\mathrm{p}}$ increased in Fig. 4. Moreover, the deterioration of the side surface of the electrode material was not generated and the large dimple reached the edge of the modified surface at $I_{\mathrm{p}}=21$. Therefore, PA-PS treatment at $I_{\mathrm{p}}=21$ with high hardness was applied to the surface of the cutting tool.

\section{Conclusions}

In this study, the characteristics of the modified surfaces treated by PS treatment on the HSS workpiece were identified using the TiC electrodes. Based on the experimental results and further discussion, the following conclusions were drawn:

(1) The diameter of a single dimple increases along with an increase in $I_{\mathrm{p}}$; however, its growth saturates after $I_{\mathrm{p}}=10 \mathrm{~A}$.

(2) The height of a peak and the depth of a crater in a discharge dimple increases along with an increase in $I_{\mathrm{p}}$; however, their growth saturates after $I_{\mathrm{p}}=10 \mathrm{~A}$.

(3) The modified layer subjected to PS treatment has rough surfaces, and the roughness of the modified surface increases as $I_{\mathrm{p}}$ increases.
(4) The Ti atomic number concentration in the modified layer increases as $V_{\mathrm{e}}$ increases for each $I_{\mathrm{p}}$.

(5) The peak shapes on the modified surfaces under $I_{\mathrm{p}}=3$ A and $I_{\mathrm{p}}=10$ and $21 \mathrm{~A}$ are sharp and dull at any $V_{\mathrm{e}}$.

(6) The modified surface treated under $I_{\mathrm{p}}=3$ A has multiple peaks, and the modified surface treated under $I_{\mathrm{p}}=10$ and $21 \mathrm{~A}$ has multiple craters.

(7) The size of "sagging" increases when $I_{\mathrm{p}}$ increases; the heights of "sagging" to the side are $\sim 8 \mu \mathrm{m}$ at $I_{\mathrm{p}}=3 \mathrm{~A}$ and $\sim 18 \mu \mathrm{m}$ at $I_{\mathrm{p}}=21 \mathrm{~A}$.

(8) The hardness of the modified surface is 300-600 HV larger than that of an untreated HSS surface. The hardness increases along with an increase in $I_{\mathrm{p}}$.

(9) PS treatment improves the friction characteristics of the surfaces of materials because of a decreasing friction coefficient under fluid lubrication.

(10) The maximum distance from the edge of the workpiece to the modified surface is $\sim 150 \mu \mathrm{m}$ when $I_{\mathrm{p}}=3$ A and $\sim 80 \mu \mathrm{m}$ when $I_{\mathrm{p}}=21$ A. Moreover, PA-PS treatment under $I_{\mathrm{p}}=21$ A successfully treated the edge of the modified surface.

Open Access This article is licensed under a Creative Commons Attribution 4.0 International License, which permits use, sharing, adaptation, distribution and reproduction in any medium or format, as long as you give appropriate credit to the original author(s) and the source, provide a link to the Creative Commons licence, and indicate if changes were made. The images or other third party material in this article are included in the article's Creative Commons licence, unless indicated otherwise in a credit line to the material. If material is not included in the article's Creative Commons licence and your intended use is not permitted by statutory regulation or exceeds the permitted use, you will need to obtain permission directly from the copyright holder. To view a copy of this licence, visit http://creativecommons.org/licenses/by/4.0/.

\section{References}

1. Yamada Y, Ikeda T (1995) Coated cutting tools—drills, endmills. JSPE 61(6):778-782

2. Kivak T (2014) Optimization of surface roughness and flank wear using the Taguchi method in milling of Hadfield steel with PVD and CVD coated inserts. Measurement 50(1):19-28

3. Sumi N, Goto A, Teramoto H, Yasunaga Y, Nakano Y (2012) Study of improvement of TiC layer by electrical discharge coating-metallographic analyses and characteristics evaluations of improved TiC layer containing Si. JSEME 46(113):133-140

4. Kibria G, Sarkar BR, Pradhan BB, Bhattacharyya B (2010) Comparative study of different dielectrics for micro-EDM performance during microhole machining of Ti-6Al-4V alloy. Int J Adv Manuf Technol 48(5):557-570

5. Mohri N, Saito N (1998) Surface modification by electrical discharge machining. JSPE 64(12):1715-1718

6. Ochiai H, Watanabe M, Arai M, Yoshizawa H (2009) MS coating; useful for life elongation and recovery of parts. IHI Tech Rep 49(4):234-243 
7. Hashimoto H, Kunieda M (1997) Spectroscopic analysis of temperature variation of EDM arc plasma. JSEME 31(68):32-40

8. Mohri N, Saitoo N, Tsunekawa Y, Moriyama H, Miyagawa A (1993) Surface modification by electrical discharge machining composite electrode method. JSPE 59(4):625-630

9. Ching-Yuan B, Chun-Hao K (2006) Effects of kerosene or distilled water as dielectric on electrical discharge alloying of superalloy Haynes 230 with Al-Mo composite electrode. Surf Coat Technol 200:4127-4135

10. Moro T, Goto A, Mohri N, Saito N, Matsukawa K, Miyake H (2001) Surface modification process by electrical discharge machining with TiC semi-sintered electrode. JSPE 67(1):114-119

11. Katou C, Egawa A, Kyoizumi T, Sumi N, Xu S, Shimsda K, Mizutani M, Kuriyagawa T (2016) Study on surface treatment by plasma discharge modification Properties evaluation of treated surface under different discharge conditions. In: 2016 JSPE autumn conference, pp 161-162

12. Salonitis K, Stournaras A, Stavropoulos P, Chryssolouris G (2009) Thermal modeling of the material removal rate and surface roughness for die-sinking EDM. Int J Adv Manuf Technol 40:316-323

13. Uno Y, Endo O, Nakajima T (1991) Fundamental aspect of the crater generation mechanism by a single pulse discharge. JSEME 25(49):9-22

14. Yoshida S, Ootake K, Kawanabe K, Kagawa Y, Isono H, Sugibayashi T (2011) Evaluation parameters of surface texture on shot-blasted surfaces. J Jpn Inst Light Met 61(5):187-191

15. Kyoizumi T, Egawa A, Shibata Y, Kato C, Sumi N, Shimada K, Mizutani M, Kuriyagawa T (2018) Low wear/low friction interface generation by plasma-shot treatment and grinding processing. J Jpn Soc Abras Technol 62(7):371-376

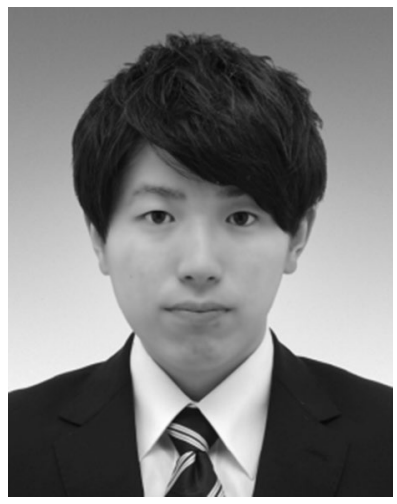

Yorihito Shibata is a Master course student at the Department of Mechanical System Engineering, Graduate School of Engineering, Tohoku University. He received the Bachelor's degree at the Department of Mechanical and Aerospace Engineering of Tohoku University in 2018. His research interest is surface texturing with Electric Discharge Machining.

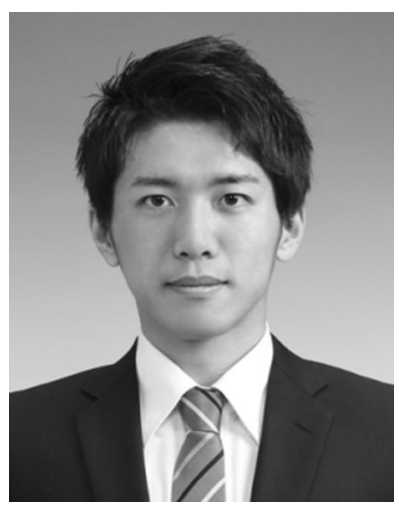

Yusuke Sakairi is a Master course student at the Department of Mechanical System Engineering, Graduate School of Engineering, Tohoku University. He received the Bachelor's degree at the Department of Mechanical and Aerospace Engineering of Tohoku University in 2019. His research interest focus on the development of nano-/microhybrid texturing method with Non-conventional machining process.

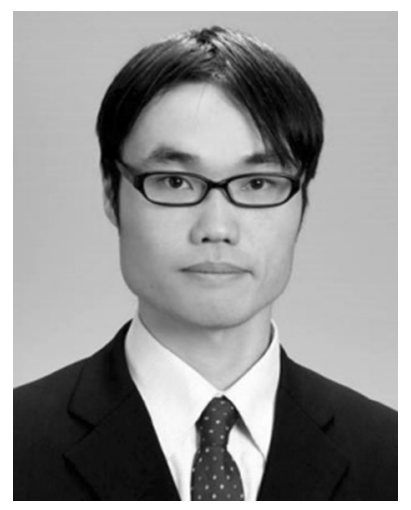

Keita Shimada is an Assistant Professor at the Department of Mechanical System Engineering, Graduate School of Engineering, Tohoku University. He received his Ph.D. from Tohoku University in 2012. His main research interests focus on the calculation and simulation of mechanical machining process.

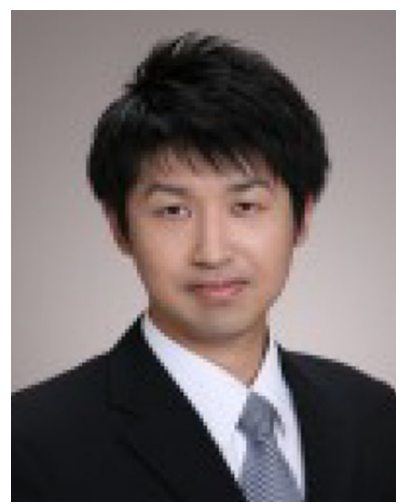

Masayoshi Mizutani is an Associate Professor at the Department of Mechanical System Engineering, Graduate School of Engineering, Tohoku University. He received his Ph.D. from Keio University in 2006. His main research interests focus on the applications of nano-/microhybrid textured surface and on the creation of the functional interface for bio-medical applications.

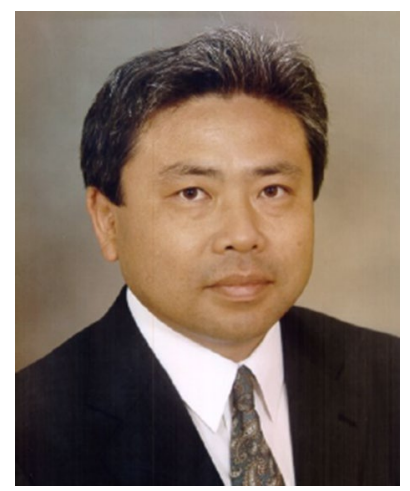

Tsunemoto Kuriyagawa is a Professor at the Graduate School of Biomedical Engineering, Tohoku University. He received his Ph.D. from Tohoku University in 1990. His main research interests are Nano-Precision Mechanical Manufacturing, Micro/Meso Mechanical Manufacturing (M4 process) and Powder Jet Deposition. 